Check for updates

Cite this: RSC Adv., 2017, 7, 34339

Received 14th March 2017

Accepted 5th June 2017

DOI: $10.1039 / c 7 r a 03039 h$

rsc.li/rsc-advances

\section{Exploring the pathways of aromatic carboxylic acids in ozone solutions}

\author{
Xin Zhong, (D) a Chongwei Cui*a and Shuili Yu ${ }^{\mathrm{b}}$
}

The reaction between ozone and natural organic matter (NOM) generates a certain amount of aromatic carboxylic acids (ACAs). Previous studies report that the pre-ozonation of fulvic acid can produce protocatechuic acid (PA), 3-hydroxybenzoic acid (3-OHBA), phthalic acid (PhA), and benzoic acid (BA). Ozonation of ACAs may result in diverse, low-molecular-weight carbonyl compounds, significantly affecting the formation of disinfection by-products (DBPs) following chlorination. The purpose of this study was to determine the degradation mechanisms, possible ozonation reaction pathways, ozonation intermediates and DBPs of four ACAs, and evaluate the ability of degrading micro-pollutants with different structures by ozonation, as well as to make up for the knowledge gap of DBPs generated. The results showed that two stages pseudo-first-order reaction for four ACAs and six intermediates accompanied the ozonation of ACAs, namely formaldehyde, glyoxal, methylglyoxal, fumaric acid, formic acid, and acetic acid. Whether the hydroxyl radical was involved or not, the ozonation of ACAs contained three steps; first step being the BA hydroxylation. Second, hydroxylation products of BA were oxidized to generate ring-opened compounds such as unsaturated carbonyl compounds. Third, short-chain aldehydes and carboxylic acids were formed. As for mineralization, the short-chain aldehydes and carboxylic acids were finally transformed into $\mathrm{CO}_{2}$ and $\mathrm{H}_{2} \mathrm{O}$. In addition, not only ACAs themselves were the main DBPs precursors, but the intermediates of ACAs ozonation could also be the DBPs precursors, and they produced high yields of trihalomethanes (THMs) and haloacetic acids (HAAs). Therefore, the ACA levels should be kept under control in drinking water treatment plants.

\section{Introduction}

Aromatic carboxylic acids (ACAs) represent a wide range of chemicals used as raw materials or generated in various industries such as printing and dyeing, pharmaceuticals, food, cosmetics and paper mills. ${ }^{1}$ All compounds are toxic and display low biodegradability. ${ }^{2,3}$ Benzoic acid (BA) is detected in the effluents of the pharmaceutical industries. ${ }^{4}$ In printing and dyeing industries, phthalic acid (PhA) is generally used as the main raw material for acylation and esterification reactions. Consequently, these ACAs can be found in diverse media, such as surface water, sediments, landfill leachate water and even in atmospheric aerosols. ${ }^{5,6} \mathrm{BA}$ (from 1.1 to $4.5 \mu \mathrm{g} \mathrm{l}^{-1}$ ) has been detected in surface water. ${ }^{7}$ PhA $\left(12.2 \pm 0.8 \mu \mathrm{g} \mathrm{l}^{-1}\right)$ has been found in tap water disinfected by ozonation combined with chlorination. $^{8}$

Ozone $\left(\mathrm{O}_{3}\right)$, an electrophile with high selectivity, is commonly used for degrading organic pollutants in water treatment plants. ${ }^{9}$ However, organic compounds containing

${ }^{a}$ School of Municipal \& Environmental Engineering, Harbin Institute of Technology, Harbin 150090, China

${ }^{b}$ School of Environmental Science and Engineering, Tongji University, Shanghai 200433, China electron-rich functional groups (e.g. double bonds, activated aromatic ring) are selectively attacked by molecular $\mathrm{O}_{3}$, while $\mathrm{OH}$ non-selectively reacts with organic compounds. ${ }^{10} \mathrm{O}_{3}$ oxidation mechanism includes molecular $\mathrm{O}_{3}$ direct reactions and ${ }^{\circ} \mathrm{OH}$ indirect reactions that are produced by $\mathrm{O}_{3}$ decomposition. Currently, some electron-rich moieties and hydroxylation products are intermediately formed during ozonation. ${ }^{11-14}$ On the contrary, aromatics structures containing electron-withdrawing functional groups how activated $\mathrm{O}_{3}$ as well as intermediate products received little attention. For one thing, aromatic compounds containing electron-withdrawing functional groups (e.g. $-\mathrm{Cl}$, $-\mathrm{COOH},-\mathrm{NO}_{2},-\mathrm{CN}$ ) are generally $\mathrm{O}_{3}$ resistant. For another thing, they could be effectively oxidized by ${ }^{\circ} \mathrm{OH}$, with second-order rate constants ranging from $10^{8}$ to $\sim 10^{10} \mathrm{M}^{-1} \mathrm{~s}^{-1} \cdot{ }^{15}$

Some researchers have reported the selectivity of compounds with similar chemical structures during ozonation process. Zhang and Croué selected six carboxylic acids, namely acetic acid, oxalic acid, citric acid, pyruvic acid, malonic acid and succinic acid, to study their reactivity with molecular $\mathrm{O}_{3}$, and the results demonstrated that their reactivity was low. ${ }^{16}$ Their results clearly demonstrated that ozonation could not completely degrade the carboxylic acids. Huang et al., reported that though BA is recalcitrant to $\mathrm{O}_{3}$ attack, it undergoes efficient degradation at an acidic $\mathrm{pH}(2.3) .{ }^{15}$ The degradation of BA and 
$\mathrm{O}_{3}$ decomposition were both enhanced on increasing the BA concentration. Our previous studies showed that the preozonation of fulvic acid can produce protocatechuic acid (PA), 3-hydroxybenzoic acid (3OHBA), PhA, and BA, which could continue to react with $\mathrm{O}_{3}$ during the main ozonation step in the treatment of drinking water. It is noteworthy that their chemical structures are closely similar (containing different numbers of $-\mathrm{COOH}$ and $-\mathrm{OH}$ groups). However, considering the course of degradation and mineralization, the knowledge about diverse chemical structures of ACAs was not adequate, probably due to the lack of a suitable analytical method. ACAs should be converted into weaker polar and stable derivates so that they can be applicable for GC determination. In order to avoid the complex procedures of derivatization, our team employed solid phase extraction-ultra high performance liquid chromatography (SPEUPLC) to determine the level of ACAs. Moreover, ozonation of ACAs may result in diverse low-molecular-weight carbonyl byproducts, significantly affecting the formation of disinfection by-products (DBPs) following chlorination.

Although $\mathrm{O}_{3}$ has long been used for disinfection and oxidation in water treatments, there is a critical gap in information related to the transformation of organic compounds. This has become increasingly important in recent years because there is a considerable concern about the formation of potentially harmful degradation products and oxidation products from the reaction with the matrix components. Thus, the purpose of this study was to investigate the degradation mechanism, possible ozonation reaction pathways, ozonation intermediates and DBPs of 4 ACAs, evaluate the ability of degrading micropollutants with different structures by ozonation, and make up for the knowledge gap of the generated DBPs.

\section{Materials and methods}

\subsection{Materials}

The analytical standard including 15 carbonyl compounds (formaldehyde, acetaldehyde, propanal, butanal, pentanal, hexanal, cyclohexanone, crotonaldehyde, heptanal, octanal, benzaldehyde, nonanal, decanal, glyoxal and methyl glyoxal) and the derivatization reagent O-(2,3,4,5,6-pentafluorobenzyl) hydroxylamine (PFBOA) were purchased from Acc Standard (New Haven, USA). HPLC grade $n$-hexane from Anpel (Shanghai, China) was used as a solvent for the liquid-liquid extraction. The Synergy UV-Ultrapure Water System (Millipore, Molsheim, France) provided organic-free water.

Standards of the 7 carboxylic acids ( $>95 \%$ purity), formic acid, acetic acid, fumaric acid, PA, 3-OHBA, PhA and BA, were purchased from J\&K (Beijing, China). Hydrochloric acid, sodium hypochlorite, sodium hydroxide, potassium dihydrogenphosphate and orthophosphoric acid were analytically pure and supplied by Shanghai (Shanghai, China). Silica-reverse phase sorbent (Supelclean ENVI-18) containing octadecyl functional groups, was purchased from Supelco (Bellefonte, PA, USA). LiChrolut EN (particle size $40-120 \mu \mathrm{m}$ ) was provided by Merck (Darmstadt, Germany).

\subsection{Experimental procedures}

Stock solutions of 4 ACAs were prepared by dissolving $1.0 \mathrm{~g}$ ACAs in $1000 \mathrm{ml}$ purified water and mixing for $24 \mathrm{~h}$, individually. Working solutions at $1.0 \mathrm{mg} \mathrm{l}^{-1}$ concentration were obtained by water dilution. All these solutions were stored at $4{ }^{\circ} \mathrm{C}$.

All ozonation experiments were operated on $500 \mathrm{ml}$ SIMAX bottles fitted with a magnetic stirring bar. COM-AD-01 $\mathrm{O}_{3}$ generator ( $4 \mathrm{~g} \mathrm{~h}^{-1}$, ANSEROS, Germany) produced $\mathrm{O}_{3}$ from pure $\mathrm{O}_{2}(\geq 99.2 \%$ purity). Subsequently, through a disperser placed at the bottom of the reactor, $\mathrm{O}_{3}$ was scattered rapidly into ultrapure water. According to the direct UV absorbance method, ${ }^{17}$ the concentration of $\mathrm{O}_{3}$ stock solution (15-20 $\mathrm{mg} \mathrm{l}^{-1}$ ) was measured. Phosphate buffer solution was added to ensure a uniform solution $\mathrm{pH}$ of $7( \pm 0.1)$ in all experiments. The ozonation reactions were terminated by sodium nitrite $(200 \mu \mathrm{l}$, $6.9 \mathrm{~g} \mathrm{l}^{-1}$, J\&K, Beijing, China). ${ }^{18}$ The ozonated samples were stored at $4{ }^{\circ} \mathrm{C}$ for not more than $24 \mathrm{~h}$. The experimental scheme included the following conditions: $\mathrm{O}_{3}$ contact time 1, 2, 5, 10, 20, $30 \mathrm{~min}, \mathrm{O}_{3} 1.0 \mathrm{mg} \mathrm{l}^{-1}$ and $\mathrm{pH} 7$.

Chlorination was conducted on ozonated samples using $100 \mathrm{ml}$ chlorine-free bottles. Chosen $\mathrm{Cl}_{2}$ dosage guaranteed that a sufficient amount of $\mathrm{Cl}_{2}$ remained in solution after incubation for $24 \mathrm{~h}$, and hence reactions were not limited by chlorine concentration. After chlorine was added, samples were stored headspace-free, at a pH 7 and $25 \pm 1{ }^{\circ} \mathrm{C}$ in the dark for $24 \mathrm{~h}$. Ascorbic acid was used to quench the residual chlorine $(100 \mu \mathrm{l}$, $10 \mathrm{~g} \mathrm{l}^{-1}$, Anpel, Shanghai, China).

\subsection{Analytical methods}

According to Standard Method 5310, ${ }^{17}$ the total organic carbon analyzer (OI, Aurora1030) was used to measure the decay of total organic carbon (TOC) during treatment.

The EPA 556 method and the EPA 552.2 method were individually used for the analysis of aldehydes and dichloroacetic acid (DCAA) in water samples (EPA, 1998, EPA, 2003). Aldehydes and DCAA were analyzed by 7890B gas chromatograph fitted with an electron capture detector (ECD) (Agilent Technologies, Palo Alto, USA). The DB-5MS capillary column $(30 \mathrm{~m} \times 0.25 \mathrm{~mm}$ I.D. $\times 0.25 \mu \mathrm{m}$ film thickness, Agilent Technologies, Bellefonte, PA, USA) was applied for the separation. The carrier gas was He

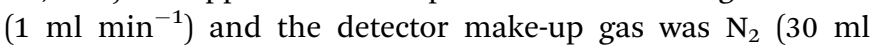
$\left.\min ^{-1}\right)$. The aldehydes temperature program was as follows: $50{ }^{\circ} \mathrm{C}$ hold for $1 \mathrm{~min}$, program at $4{ }^{\circ} \mathrm{C} \min ^{-1}$ up to $220{ }^{\circ} \mathrm{C}$, program at $20{ }^{\circ} \mathrm{C} \min ^{-1}$ up to $250{ }^{\circ} \mathrm{C}$ and hold at $250{ }^{\circ} \mathrm{C}$ for $10 \mathrm{~min}$. The DHAA temperature program was as follows: $35{ }^{\circ} \mathrm{C}$ hold for $10 \mathrm{~min}$, program at $2{ }^{\circ} \mathrm{C} \mathrm{min}^{-1}$ up to $40{ }^{\circ} \mathrm{C}$, program at $5{ }^{\circ} \mathrm{C} \mathrm{min} \min ^{-1}$ up to $75{ }^{\circ} \mathrm{C}$ and hold at $75{ }^{\circ} \mathrm{C}$ for $15 \mathrm{~min}$, program at $40{ }^{\circ} \mathrm{C} \mathrm{min} \operatorname{mos}^{-1}$ up to $100{ }^{\circ} \mathrm{C}$ and hold at $100{ }^{\circ} \mathrm{C}$ for $15 \mathrm{~min}$, program at $40{ }^{\circ} \mathrm{C} \min ^{-1}$ up to $135{ }^{\circ} \mathrm{C}$.

According to the purge and trap gas chromatographic method, chloroform was measured using 4660-7890B-5077A gas chromatograph (Agilent Technologies, Palo Alto, USA) equipped with a mass spectrometer. The operating conditions were as follows: magnetic mass analyzer scans from 35 to $200 \mathrm{~m} / \mathrm{z}, 70 \mathrm{eV}$ electron energy, ion source $250{ }^{\circ} \mathrm{C}$, carrier gas: $\mathrm{He}\left(1 \mathrm{ml} \mathrm{min}^{-1}\right)$, temperature program: $30{ }^{\circ} \mathrm{C}$ hold for $10 \mathrm{~min}$, program at $7{ }^{\circ} \mathrm{C}$ 
$\min ^{-1}$ up to $72{ }^{\circ} \mathrm{C}$ and hold at $72{ }^{\circ} \mathrm{C}$ for $1 \mathrm{~min}$, program at $40{ }^{\circ} \mathrm{C}$ $\min ^{-1}$ up to $220^{\circ} \mathrm{C}$ and hold at $220^{\circ} \mathrm{C}$ for $1 \mathrm{~min}$.

The 4 ACAs and 1 aliphatic carboxylic acid (fumaric acid, PA, 3-OHBA, PhA and BA) were analyzed by SPE-UPLC. ${ }^{19}$ The SPE system (Anpel, Shanghai, China) was assembled from a GAST pump (MICH, USA). The SPE cartridges were conditioned using $1 \mathrm{ml}$ acetonitrile-methanol $(1: 1)$ and $1 \mathrm{ml}$ ultrapure water. Chromatographic analyses were carried out on a Waters H-class Ultra high performance liquid chromatography system (Waters, USA). The column was ACQUITY UPLC BEH C18 $(2.1 \times 50 \mathrm{~mm}$ I.D., particle size $1.7 \mu \mathrm{m}$, Waters, USA). A PHS-2C pH meter (Shanghai, China) was used to adjust the $\mathrm{pH}$ value. In brief, $100 \mathrm{ml}$ standard solution or ACAs water sample at $\mathrm{pH} \sim 1.3$ (adjusted with $5 \mathrm{M} \mathrm{HCl}$ ) flowed past the SPE cartridge at 2-3 ml $\mathrm{min}^{-1}$. The SPE cartridge was filled with $80 \mathrm{mg}$ of the mixture of LiChrolut EN/Supelclean ENVI-18 $(1: 1)$ sorbents. Later, ACAs were eluted by $1 \mathrm{ml}$ methanol and collected in a $2 \mathrm{ml}$ glass GC vial.

Formic acid and acetic acid were analyzed by ICS-2100 Ion chromatograph (Thermo Scientific, USA) equipped with a Dionex IonPac AS-19 capillary column $(0.4 \mathrm{~mm} \times 250 \mathrm{~mm})$ and a Dionex IonPac AS-19 guard column $(0.4 \mathrm{~mm} \times 50 \mathrm{~mm})$. Dionex RFIC-EG eluent generator provided the mobile phase, with the following conditions: flow $10 \mu \mathrm{l} \mathrm{min}{ }^{-1}, 0-10 \mathrm{~min} 10 \mathrm{mM}$ $\mathrm{KOH}, 10-42$ min linear ramp to $52 \mathrm{mM} \mathrm{KOH,} \mathrm{42-45} \mathrm{min} \mathrm{linear}$ ramp to $70 \mathrm{mM} \mathrm{KOH,} 45-50 \mathrm{~min} 10 \mathrm{mM} \mathrm{KOH}$.

\subsection{Quality control}

Calibration curves prepared for each compound were linear $\left(R^{2}\right.$ $>0.980$ ). The method of aldehydes detection limits varied from $0.2 \mu \mathrm{g} \mathrm{l} \mathrm{l}^{-1}$ to $4.0 \mu \mathrm{g} \mathrm{\textrm {l } ^ { - 1 }}$. The method of carboxylic acids detection limits varied from $0.8 \mu \mathrm{g} \mathrm{l}^{-1}$ to $5.0 \mu \mathrm{g} \mathrm{l^{-1 }}$. The recovery rates of each compound were greater than $80 \%$. Experiments were conducted in duplicates. Relative standard deviation of the two measurements was below $15 \%$ in general. The SPSS software (IBM SPSS, version 17) was employed for statistical data analysis.

\section{Results and discussion}

\subsection{ACAs degradation by ozone}

3.1.1 Degradation mechanisms of ACAs. Previous studies have shown that the ozonation kinetics are pseudo-first-order or pseudo-second-order reactions. ${ }^{11}$ There were three main considerations for ACAs concentrations in the degradation mechanisms. First, the starting point of this study was based on the actual water treatment plant $\left(1.0 \mathrm{mg} \mathrm{l}^{-1} \mathrm{O}_{3}\right)$; second, ACAs were accurately analyzed by SPE-UPLC; finally, in order to clearly reflect the reaction course of $\mathrm{O}_{3}$ and ACAs, $1.0 \mathrm{mg} \mathrm{l}^{-1} \mathrm{BA}$, $\mathrm{PA}, \mathrm{PhA}$, and 3-OHBA were chosen. The residual concentrations of four ACAs were detected at different contact times in order to determine the reaction rates.

It is generally recognized that under acidic conditions, molecule $\mathrm{O}_{3}$ is the primary active substance, whereas under basic conditions, ${ }^{\circ} \mathrm{OH}$ is the primary active substance. In addition, $\mathrm{O}_{3}$ not only depletes by reaction with ACAs, but also by self- degradation in the ultrapure water. Hence, first-order reactions were not observed during the monitoring period. On the contrary, the reactions could be expressed in two steps pseudofirst-order reactions, as shown in Fig. 1. It is clearly noticed that the reactivity was in the order $\mathrm{PA}>3-\mathrm{OHBA}>\mathrm{BA}>\mathrm{PhA}$. Previous studies have indicated that $\mathrm{O}_{3}$ directed oxidation was effective for degradation of organic pollutants bearing active groups, such as $-\mathrm{OH},-\mathrm{NH}_{2}$, and double bond. ${ }^{10,11}$ The existence of active groups was advantageous for $\mathrm{O}_{3}$ for the electrophilic attack on the aromatic ring. Thus, this was more significant for PA (bearing two electron-donating groups), resulting in a rapid degradation. In addition, carboxylate group enhanced the nucleophilicity of reaction site, further activating the reaction with $\mathrm{O}_{3}$.

These reaction rates are not only the function of the concentration of $\mathrm{O}_{3}$ and ${ }^{\circ} \mathrm{OH}$ radicals, but are also dependent on other oxidative species, therefore these reaction rates cannot be regarded as fundamental degradation mechanisms. It should be pointed out that although different aromatic groups result in different reaction rates, the degradation trends of ACAs are found to be similar. It can be inferred that the ozonation pathway for degrading ACAs could form similar by-products before the mineralization step.

There was about $39.7 \%$ of $\mathrm{PhA}, 43.3 \%$ of $\mathrm{BA}, 46.2 \%$ of 3 OHBA and $49.3 \%$ of PA degradation observed in $10 \mathrm{~min}$. As the initial reaction stage proceeds rapidly, it could be advantageous to regulate ozonation treatment in water treatment plants, particularly for $\mathrm{O}_{3}$ active components.

During ozonation, although ACAs were degraded, the mineralization degree was not high, as evidenced by the TOC measurement (Fig. 2). The mineralization degree of PA, 3OHBA, BA, and PhA was $28.8 \%, 24.2 \%, 20.9 \%, 16.2 \%$ at $30 \mathrm{~min}$, respectively. This implied the formation of ozonation byproducts. Although $\mathrm{O}_{3}$ is a strong oxidizer with selectivity, it cannot mineralize the inert organics in a given time. ${ }^{20}$ The transformation products detected during the ozonation processes are discussed in the next section.

3.1.2 By-products of ozonation ACAs. Under the cycles of continuous oxidation-decarboxylation, aromatic ring breakdown results in the generation of a series of ring-opening compounds, for example, the short-chain aldehydes and carboxylic acids. Six intermediate compounds accompanying the ozonation of ACAs, namely, formaldehyde, glyoxal, methyl glyoxal, formic acid, acetic acid and fumaric acid were shown in Fig. 3 , which were generally detected in the ozonation of aromatic compounds. ${ }^{11,20-22}$ Since formic, acetic and fumaric acids were relatively inert to $\mathrm{O}_{3}$, they were accumulated in the $\mathrm{O}_{3}$ treated water as being the end products. However, initially, the concentration of formaldehyde, glyoxal and methyl glyoxal gradually increased with the contact time. Maximum concentrations were achieved at 5-10 min and decreased thereafter. On one hand, ozonation cleaves unsaturated aliphatic chain, opens rings, removes and oxidizes alkyl groups to aldehydes; on the other hand, carboxylic acids are generated from corresponding aldehydes that are oxidized. Moreover, Liu et al., reported that oxidation rates of aldehydes were typically lower than formation rates, resulting in the accumulation in the treated water. ${ }^{23}$ 

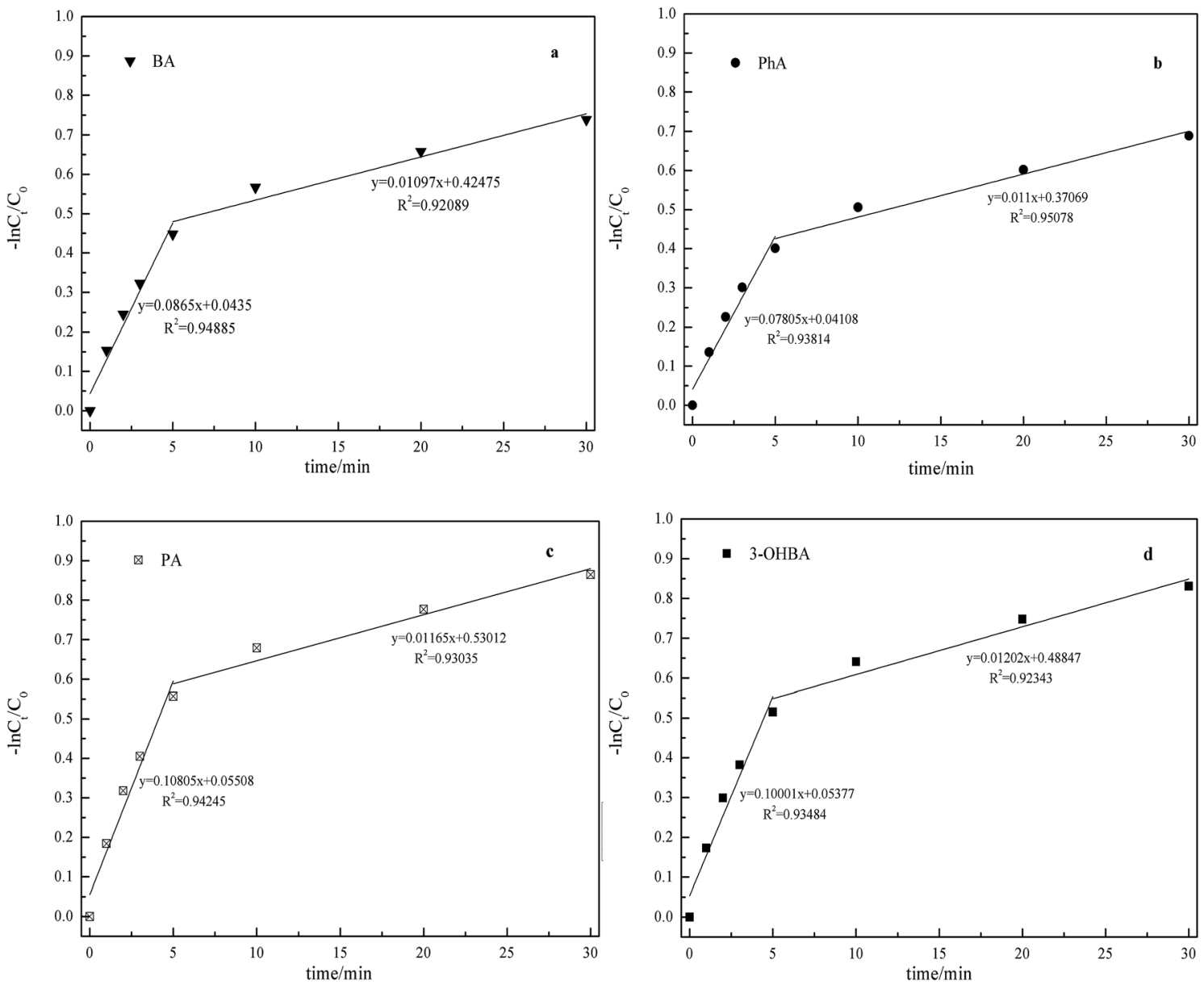

Fig. 1 Degradation of BA, PA, PhA and 3-OHBA at different contact times. Conditions: $\mathrm{pH} 7,25^{\circ} \mathrm{C},\left[\mathrm{O}_{3}\right]_{0}=1.0 \mathrm{mg} \mathrm{l^{-1 }}$, and [BA, PA, PhA, 3$\mathrm{OHBA}_{0}=1.0 \mathrm{mg} \mathrm{l}^{-1}$; (a) BA; (b) PhA; (c) PA; (d) 3-OHBA.

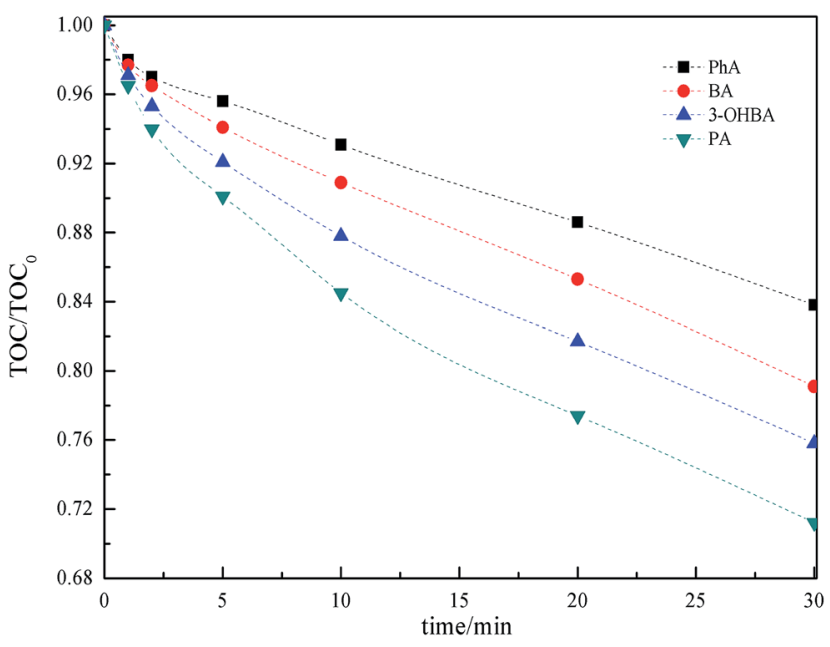

Fig. 2 TOC decay during ozonation of ACAs. Conditions: $\mathrm{pH} 7,25^{\circ} \mathrm{C}$ $\left[\mathrm{O}_{3}\right]_{0}=1.0 \mathrm{mg} \mathrm{l}^{-1}$, and $[\mathrm{BA}, \mathrm{PA}, \mathrm{PhA}, 3-\mathrm{OHBA}]_{0}=1.0 \mathrm{mg} \mathrm{l}^{-1}$.

For PhA and 3-OHBA, formic acid was the main by-product. However, for BA and PA, the main by-products were formic acid and acetic acid. Due to the different concentration levels of formic acid and acetic acid, the amount of formed formic and acetic acids relates to the chemical structure of the ACAs. In addition, it should be noted that, during the initial phase of $\mathrm{O}_{3}$ oxidation of BA, 3-OHBA was detected with a concentration ranging from $6.2 \mu \mathrm{g} \mathrm{l}^{-1}$ to $23.6 \mu \mathrm{g} \mathrm{l}^{-1}$ and then quickly disappeared. Since 3-OHBA could be further oxidized by excess $\mathrm{O}_{3}$, it was not easily detected. Pillar et al., also reported that the reaction rate constants of hydroxybenzoic acids with $\mathrm{O}_{3}$ and 'OH were $5.2 \times 10^{5} \mathrm{M}^{-1} \mathrm{~s}^{-1}$ and $1.1 \times 10^{10} \mathrm{M}^{-1} \mathrm{~s}^{-1}$, respectively. ${ }^{24}$ Moreover, Huang et al., found a significant increase in $\mathrm{OH}$ production in the presence of hydroxybenzoic acids. ${ }^{15}$ Their results indicated that hydroxybenzoic acids could promote $\mathrm{O}_{3}$ decomposition to generate ${ }^{\circ} \mathrm{OH}$. These results indicated that BA containing hydroxyl groups was easily eliminated with $\mathrm{O}_{3}$. It can be concluded that hydroxylation products were the main products of ozonation transformation organics, and the formation of formic acid, acetic acid and fumaric acid may have resulted from further oxidation of these hydroxylation products.

Carboxylic acids are an important type of newly formed assimilable organic carbon (AOC), which are a significant part of organic DBPs in drinking water ozonation treatment plants. ${ }^{7,25}$ Generally, compared to the precursors, the short- 

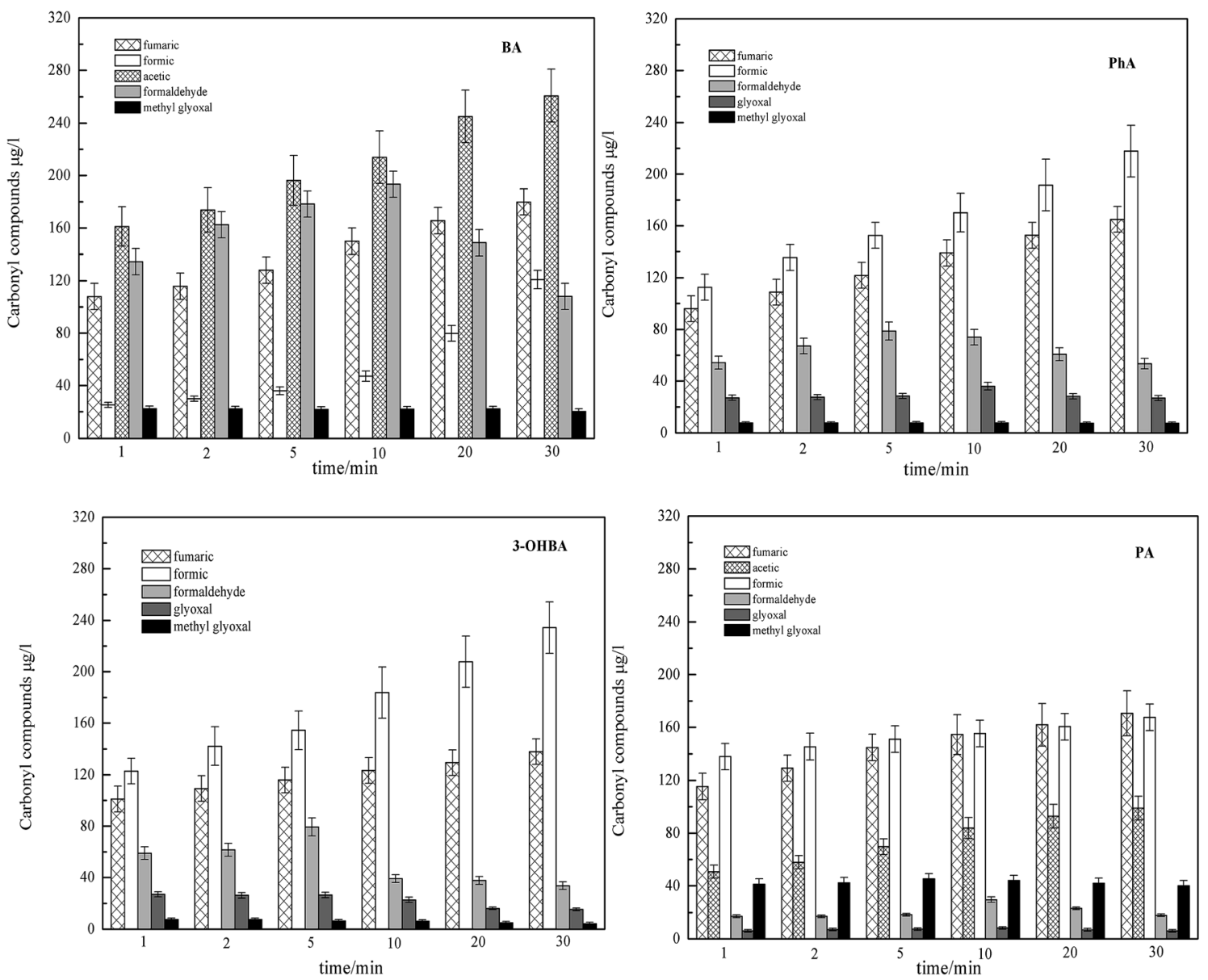

Fig. 3 The concentration of intermediates during ozonation of ACAs at different contact times. Conditions: $\mathrm{pH} 7,25^{\circ} \mathrm{C},\left[\mathrm{O}_{3}\right]_{0}=1.0 \mathrm{mg} \mathrm{l}^{-1}$, and $[\mathrm{BA}, \mathrm{PA}, \mathrm{PhA}, 3-\mathrm{OHBA}]_{0}=1.0 \mathrm{mg} \mathrm{l^{-1 }}$.

chain carboxylic acids are easily biodegradable, and they have been proven to be associated with bacterial re-growth and biofilm formation in water distribution systems. Therefore, certain measures should be adopted to control the source of carboxylic acids in drinking water treatment plants.

3.1.3 Possible pathway of ozonation of ACAs. Several studies have reported on $\mathrm{O}_{3}$ and ${ }^{\circ} \mathrm{OH}$ reacting with phenol, chlorophenol, alkene, salicylic acid and so on. Based on previous research as well as taking the experimental results into consideration, the progress of ACAs ozonation and the formation mechanisms of intermediate products were speculated and are described in Fig. 4. For example, the reaction mechanism of BA ozonation could contain three steps; the first step being BA hydroxylation. Second, the hydroxylation products of BA are oxidized to generate ring-opened compounds, and unsaturated carbonyl compounds are generated. In the third step, the shortchain aldehydes and carboxylic acids are formed. As for mineralization, the short-chain aldehydes and carboxylic acids are finally transformed into $\mathrm{CO}_{2}$ and $\mathrm{H}_{2} \mathrm{O}$.

In $\mathrm{O}_{3}$ solution, the reaction between $\mathrm{O}_{3}$ and aromatic compounds hinged largely on the electron-donating/withdrawing properties of the functional groups. $-\mathrm{COOH}$ being a strong electron-withdrawing group, results in a more electron-deficient ortho/para-position as compared to the meta-position, and therefore meta-position is the first to undergo addition. Therefore, in the reaction between $\mathrm{O}_{3}$ and $\mathrm{BA}$, the electrophilic group generally attacks the meta-position, which leads to the formation of 3-OHBA. This could explain why 3-OHBA was detected in the process of BA ozonation. On the contrary, $-\mathrm{OH}$ results in a more electron-rich ortho/para-position compared to meta-position, at the same time making the benzene ring more nucleophilic. In summary, the combined action of $-\mathrm{COOH}$ and $-\mathrm{OH}$ on the electron distribution may lead to a more electron-rich at position 5 than position 4 and 6 in 3-OHBA. This could presumably result in the formation of polyhydroxylated aromatic products. As described above, hydroxylation aromatic intermediates react rapidly with $\mathrm{O}_{3}$. Therefore, PA was not detected during 3-OHBA ozonation. Moreover, the effect of - $\mathrm{COOH}$ steric hindrance should be taken into consideration. Several researchers also reported that the first step of the ozonation degradation pathway, the formation of polyhydroxylated aromatic products, was a predominant route..$^{1,11,15,26-28}$

At the same time, these hydroxylation aromatic intermediates were further oxidized, leading to the ring opening by cycloaddition and formation of a compound containing two carboxylic groups. Through Criegee mechanism, this compound could be further decomposed into short-chain aldehydes (formaldehyde, glyoxal, 


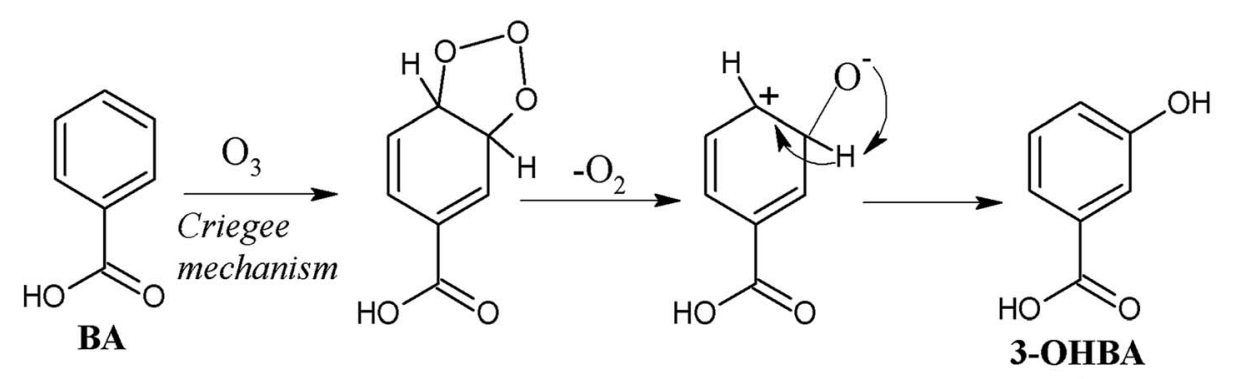

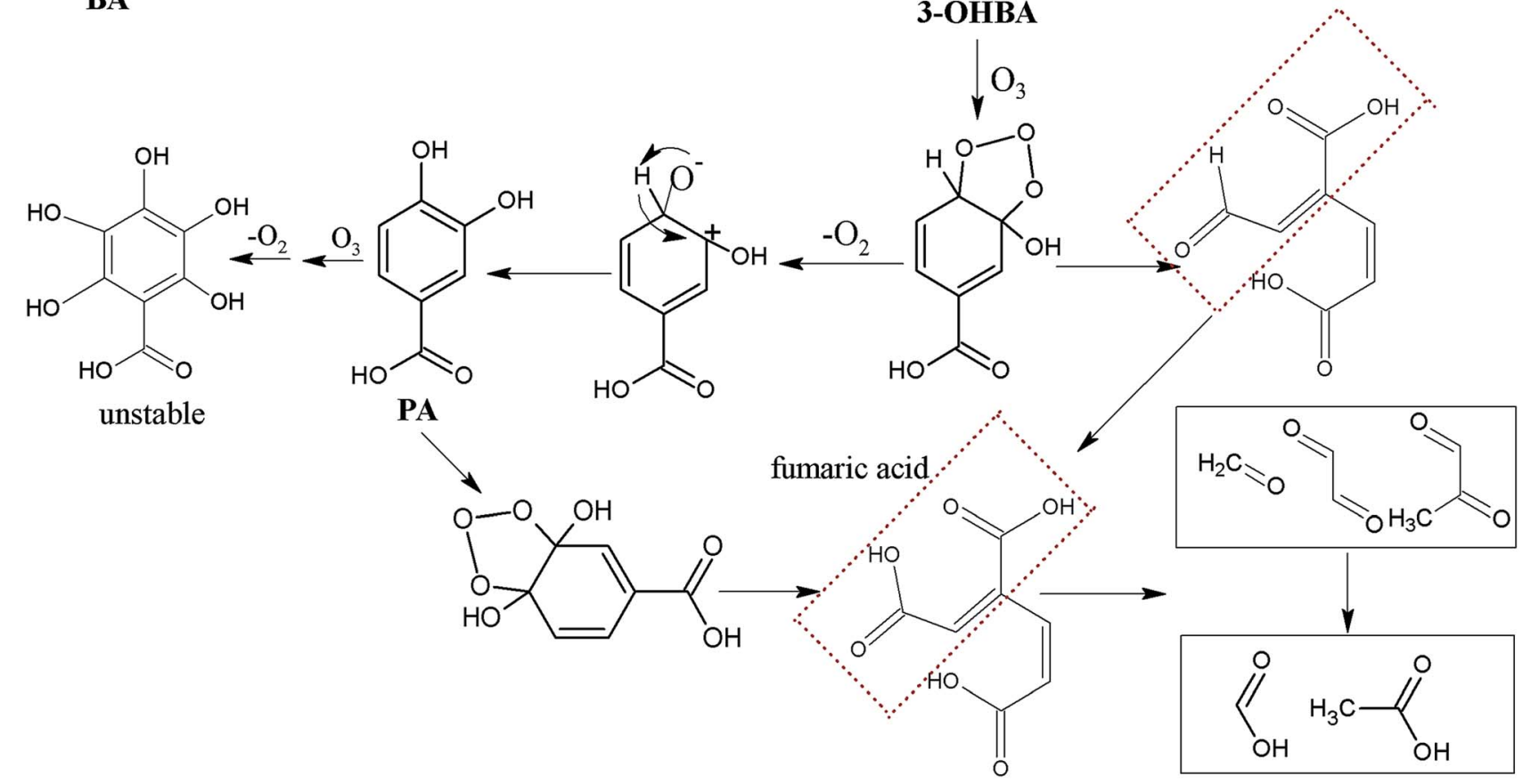

Fig. 4 Possible reaction pathways of benzoic acid moieties during their reaction with $\mathrm{O}_{3}$.

methyl glyoxal) and carboxylic acids (formic acid and acetic). ${ }^{29}$ Finally, aldehydes were constantly oxidized to form the corresponding carboxylic acid through a nucleophilic mechanism, and some of them could be completely mineralized to $\mathrm{CO}_{2}$. Instead, due to the stability of carboxylic acids in $\mathrm{O}_{3}$ solution, particularly formic and acetic acids, they would be accumulated in the solution.

Beyond that, ${ }^{\cdot} \mathrm{OH}$ radical, which was generated from $\mathrm{O}_{3}$ decomposition in water, may play an important role during the ozonation processes; the reaction of ' $\mathrm{OH}$ with $\mathrm{BA}$ was proposed and is illustrated in Fig. 5. Most ${ }^{\circ} \mathrm{OH}$ reactions are analogous to diffusion-controlled reactions and generally have the following three mechanisms: $\mathrm{H}$-atom abstraction, ${ }^{\circ} \mathrm{OH}$ addition to $\mathrm{C}-\mathrm{C}$, and ${ }^{\circ} \mathrm{OH}$ interaction with compounds containing $\mathrm{S}, \mathrm{N}$, or $\mathrm{P}$ atoms. In addition, ${ }^{\circ} \mathrm{OH}$ is more susceptible to add to $\mathrm{C}=\mathrm{C}$ rather than $\mathrm{C}=\mathrm{O}$, as the carbon atom is electron deficient. Since most radical reactions are composed of chain reactions, the generation of other radicals and electron transfer reactions occur rarely. Thus, these intermediates may not experience addition and $\mathrm{H}$-abstraction. ${ }^{11}$

BA mainly reacting with ${ }^{\circ} \mathrm{OH}$ may generate radical intermediates through addition reaction, resulting in the generation of hydroxylation aromatic products such as 3-OHBA and PA. Subsequently, $\mathrm{O}_{3}, \cdot \mathrm{OH}$ and other oxidizers would further decompose hydroxylation aromatic products, resulting in the formation of ring-open products through ${ }^{\circ} \mathrm{OH}$ addition reactions and Criegee mechanism that is similar to the reaction illustrated in Fig. 4.

\subsection{DBPs formation by ozonation of ACAs}

As shown in Fig. 6, direct chlorination disinfection and ozonation-chlorination disinfection of ACAs generated a certain amount of chloroform and DCAA, and the chlorination conditions were as follows: $\mathrm{pH} 7,25 \pm 1{ }^{\circ} \mathrm{C}$ in the dark for $24 \mathrm{~h}$. ACAs ozonation promoted the production of DCAA, and the increasing levels of BA and PA were found to be higher than 3OHBA and PhA. A consistent trend was observed for chloroform formation; ACAs ozonation also promoted the production of chloroform, whereas PA exhibited chloroform yield reductions. This result was in agreement with the results of our previous study on the raw water of Taihu Lake, where the formation potential of THMs and HAAs was improved through preozonation step. Thus, this phenomenon suggested that the amount of DOC was not a proper indicator for determining the relative abundance of the precursors of chloroform and DCAA in these experiments. In addition, the concentrations of chloroform and DCAA reach a maximum when $\mathrm{O}_{3}$ reacts with ACAs at 2-5 min and then decrease over time following $\mathrm{O}_{3}$ 


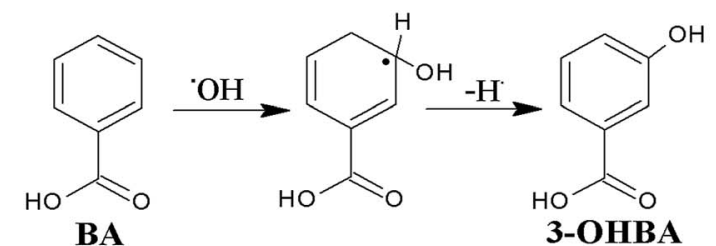

BA 3-OHBA

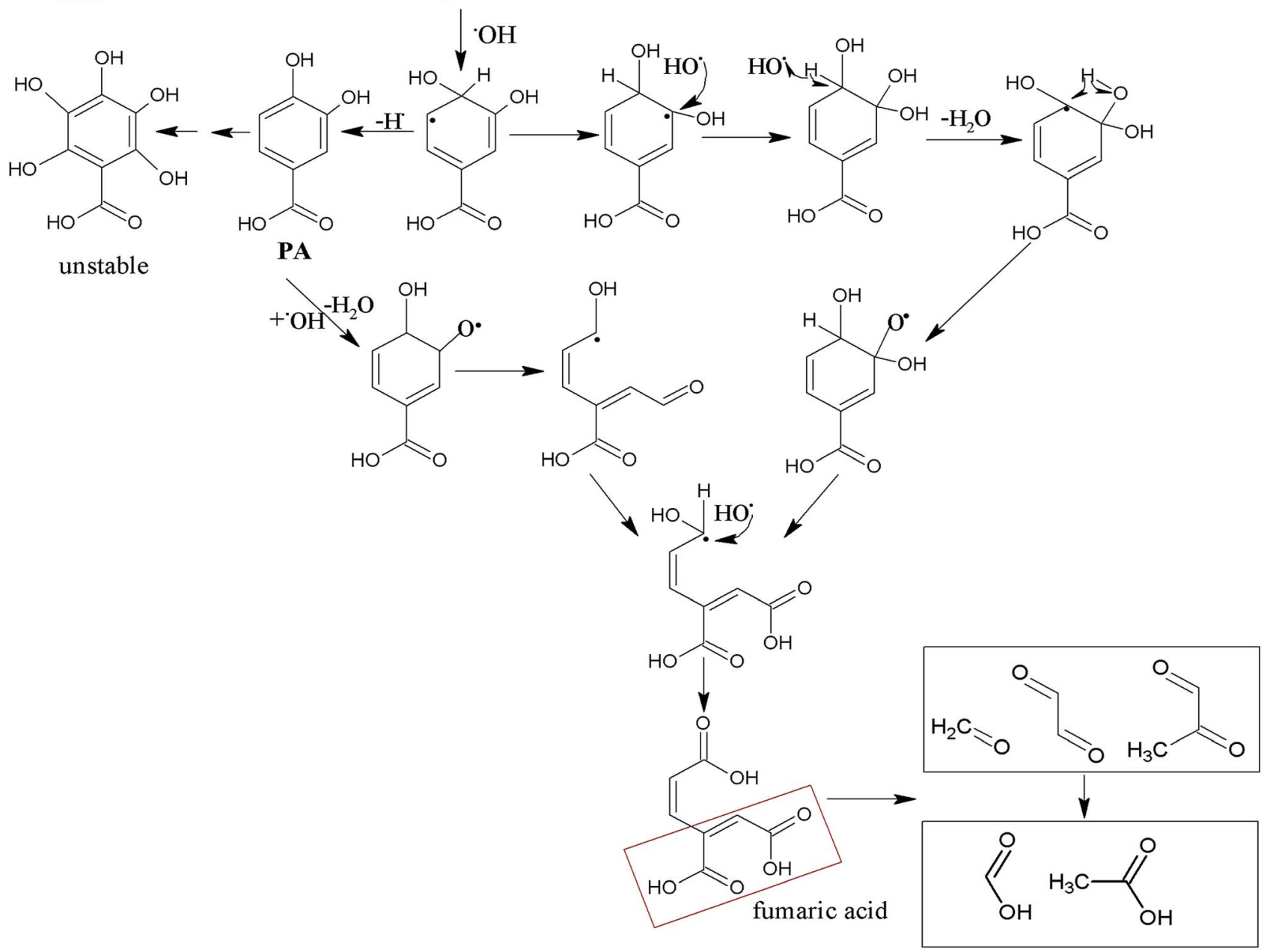

Fig. 5 Possible reaction pathways of benzoic acid moieties during their reaction with ${ }^{\circ} \mathrm{OH}$.

application. The effect of ozonation on the reduction of chloroform and DCAA was significant initially and then slowed down. It also should be noted that chloroform was the main product of ozonation-chlorination reactions of ACAs; the more reactive groups it contained, the greater the amount of DBPs generated.

It is widely assumed that chlorine reacts with the electrondonating group of aromatic compounds through electrophilic substitution and ortho/para-position stepwise chlorination, resulting in the formation of THMs. However, in the presence of an electron-withdrawing group, meta-position is progressively substituted by chlorine, resulting in the formation of THMs. Besides, resorcinol structures are popularly regarded as the most important THMs precursors. ${ }^{30,31}$ Although $\mathrm{O}_{3}$ can decompose THMs or HAA precursors, $\mathrm{O}_{3}$ intermediate products have a higher potential to form DBPs compared to the precursors. $^{32}$ Combining the results of the aforementioned research studies and literature, it can be assumed that during ACAs ozonation, the formed hydroxylation aromatic intermediates could be the main precursors. In addition, ACAs ozonation leads to short-chain aldehydes and carboxylic acids formation (e.g. formaldehyde, glyoxal, methyl glyoxal, formic acid, acetic acid and fumaric acid). During decarboxylation, the structure of these short-chain aldehydes and carboxylic acids tend to be converted into that of $\beta$-ketoacids and give high yields of THMs at solutions with $\mathrm{pH}$ around 7. As far as the DCAA formation was concerned, hydroxyl and carboxyl groups were found to be prone to generate DCAA. ${ }^{33}$

Not only were the ACAs primary DBPs precursors, the intermediates of ACAs ozonation also could be DBPs precursors, and they produced high yields of THMs and HAAs. Previous study demonstrated the ubiquitous presence of fulvic acid in the 

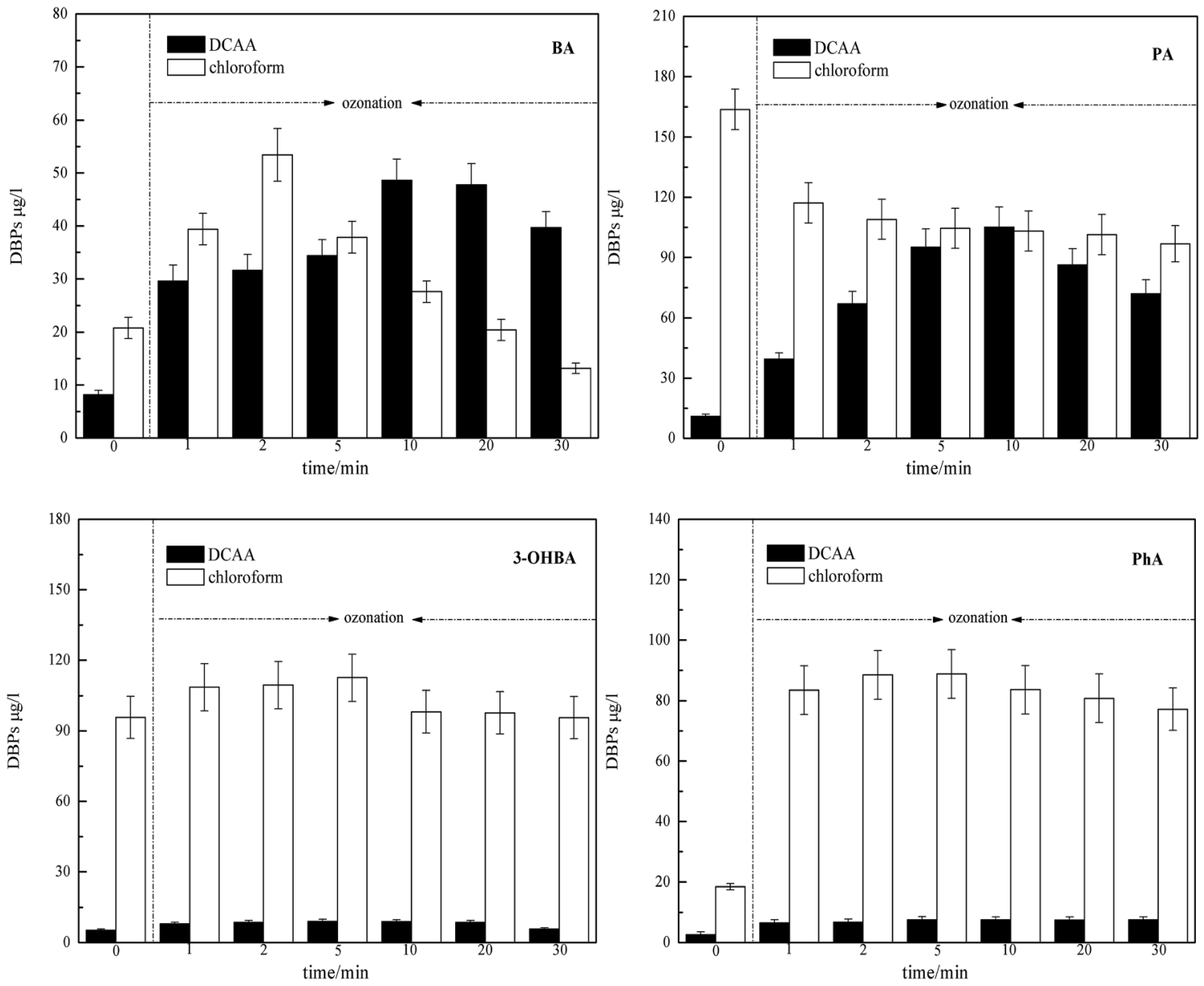

Fig. 6 Formation of DBPs during ozonation-chlorination disinfection of ACAs.

terrestrial environment and that it generated a certain amount of ACAs and low-molecular-weight carbonyl compounds during ozonation. Therefore, the ACA levels should be kept under control in drinking water treatment plants.

\section{Conclusions}

Previous studies suggest that fulvic acid ozonation can produce ACAs, such as protocatechuic acid, 3-hydroxybenzoic acid, phthalic acid, and benzoic acid, to investigate ozonation kinetics, possible ozonation reaction pathways, ozonation intermediates and DBPs of 4 ACAs. The following conclusions were obtained:

(1) Two stages pseudo-first-order reaction for 4 ACAs was carried out at $\mathrm{pH} 7,25^{\circ} \mathrm{C},\left[\mathrm{O}_{3}\right]_{0}=1.0 \mathrm{mg} \mathrm{l}^{-1}$ and [BA, PA, PhA, 3$\mathrm{OHBA}]_{0}=1.0 \mathrm{mg} \mathrm{l}^{-1}$.

(2) Six intermediates accompanied the ozonation of ACAs, namely fumaric acid, formic acid, acetic acid, formaldehyde, glyoxal and methyl glyoxal.

(3) Independent of the involvement of the hydroxyl radical, the ozonation of ACAs comprised three steps; first step was BA hydroxylation. Second, hydroxylation products of BA were oxidized to generate ring-opened compounds, and unsaturated carbonyl compounds were generated. Third, short-chain aldehydes and carboxylic acids were formed. As for mineralization, the short-chain aldehydes and carboxylic acids were finally transformed into $\mathrm{CO}_{2}$ and $\mathrm{H}_{2} \mathrm{O}$.

(4) Not only ACAs themselves were the main DBPs precursors, but the intermediates of ACAs ozonation could also be the DBPs precursors, and they produced high yields of THMs and HAAs. Therefore, the ACA levels should be kept under control in drinking water treatment plants.

\section{Acknowledgements}

This study was performed with financial support from the National Water Pollution Control and Major Projects of Science and Technology Management, Item No. 2012ZX07403001. The authors gratefully acknowledge the assistance of Wujiang HuaYan Water Co. Ltd.

\section{References}

1 N. Milovac, D. Juretic, H. Kusic, J. Dermadi and A. L. Bozic, Ind. Eng. Chem. Res., 2014, 53, 10590-10598.

2 T. Velegraki, E. Nouli, A. Katsoni, I. V. Yentekakis and D. Mantzavinos, Appl. Catal., B, 2011, 101, 479-485. 
3 M. M. Abdel Daiem, J. Rivera-Utrilla, R. Ocampo-Pérez, J. D. Méndez-Díaz and M. Sánchez-Polo, J. Environ. Manage., 2012, 109, 164-178.

4 V. G. Gandhi, M. K. Mishra, M. S. Rao, A. Kumar, P. A. Joshi and D. O. Shah, J. Ind. Eng. Chem., 2011, 17, 331-339.

5 S. Garcia-Segura, R. Salazar and E. Brillas, Electrochim. Acta, 2013, 113, 609-619.

6 T. Velegraki, G. Balayiannis, E. Diamadopoulos, A. Katsaounis and D. Mantzavinos, Chem. Eng. J., 2010, 160, 538-548.

7 B. Jurado-Sánchez, E. Ballesteros and M. Gallego, Water Res., 2014, 51, 186-197.

8 B. Jurado-Sánchez, E. Ballesteros and M. Gallego, J. Chromatogr. A, 2010, 1217, 7440-7447.

9 A. Papageorgiou, D. Voutsa and N. Papadakis, Sci. Total Environ., 2014, 481, 392-400.

10 U. von Gunten, Water Res., 2003, 37, 1443-1467.

$11 \mathrm{R} . \mathrm{Hu}, \mathrm{L}$. Zhang and J. Hu, Chemosphere, 2016, 153, 394-404.

12 G. Wen, J. Ma, Z. Liu and L. Zhao, J. Hazard. Mater., 2011, 195, 371-377.

13 K. S. Tay, N. A. Rahman and M. R. B. Abas, Chemosphere, 2010, 81, 1446-1453.

14 K. S. Tay, N. A. Rahman and M. R. B. Abas, Chemosphere, 2009, 76, 1296-1302.

15 X. Huang, X. Li, B. Pan, H. Li, Y. Zhang and B. Xie, Water Res., 2015, 73, 9-16.

16 T. Zhang and J. Croué, Appl. Catal., B, 2014, 144, 831-839.

17 APHA (American Public Health Association), American Water Works Association, Water Environment Federation, Standard Methods for the Examination of Water and Wastewater, American Public Health Association, Washington, DC, 20th edn, 1999.

18 F. Hammes, E. Salhi, O. Köster, H. Kaiser, T. Egli and U. von Gunten, Water Res., 2006, 40, 2275-2286.
19 X. Zhong, C. W. Cui and S. L. Yu, China Water Wastewater, 2016, 32, 107-112.

20 D. Magallanes, J. L. Rodriguez, T. Poznyak, M. A. Valenzuela, L. Lartundo and I. Chairezd, New J. Chem., 2015, 39, 78397848.

21 M. Pariente, F. Martinez, J. Melero, J. Botas, T. Velegraki, N. Xekoukoulitakis and D. Mantzavinos, Appl. Catal., B, 2008, 85, 24-32.

22 D. Shahidi, A. Moheb, R. Abbas, S. Larouk, R. Roy and A. Azzouz, J. Hazard. Mater., 2015, 298, 338-350.

23 C. Liu, X. Tang, J. Kim and G. V. Korshin, Chemosphere, 2015, 125, 182-190.

24 E. A. Pillar, R. C. Camm and M. I. Guzman, Environ. Sci. Technol., 2014, 48, 14352-14360.

25 T. Zhang, J. Lu, J. Ma and Z. Qiang, Water Res., 2008, 42, 1563-1570.

26 C. Y. Chang, Y. H. Hsieh, K. Y. Cheng, L. L. Hsieh, T. C. Cheng and K. S. Yao, Water Sci. Technol., 2008, 58, 873-879.

27 D. M. Theodora Velegraki, Chem. Eng. J., 2008, 140, 15-21.

28 J. Wenk, M. Aeschbacher, E. Salhi, S. Canonica, U. von Gunten and M. Sander, Environ. Sci. Technol., 2013, 47, 11147-11156.

29 R. Criegee, Angew. Chem., Int. Ed., 1975, 14, 745-752.

30 T. Bond, O. Henriet, E. H. Goslan, S. A. Parsons and B. Jefferson, Environ. Sci. Technol., 2009, 43, 5982-5989.

31 K. K. Philippe, C. Hans, J. Macadam, B. Jefferson, J. Hart and S. A. Parsons, Chemosphere, 2010, 81, 1509-1516.

32 F. Qi, B. Xu, Z. Chen, L. Feng, L. Zhang and D. Sun, Chem. Eng. J., 2013, 219, 527-536.

33 A. Li, X. Zhao, H. Liu and J. Qu, Water Res., 2011, 45, 61316140. 